189

564 Patients with Acute Chest Pain in Emergency Room: Clinical Evaluation and Predictive Instrument

Pierini A, * Sardella $F$,** Checchini $M$, ** Rigiletti $G$, ${ }^{* *}$ Negrini $M$, ** Rovey $R,{ }^{* *}$ Molteni $G$, Omboni $E^{* * *}$

* Emergency Department Ospedale Maggiore

** Emergency Department, Ospedale Fatebenefratelli Milano, Italy

Objective: A predictive instrument was developed to improve the diagnostic procedure in managing patients with chest pain (CP) and suspicion of acute ischemic heart disease (AIHD).

Methods: Five-hundred-sixty-four patients with a chief symptom of CP (348 male, 216 female, mean age $57.2 \pm 13.2$ yrs) seen in the emergency department (ED) between October 1989 and November 1992, without active myocardial infarction, were included in this study. Clinical and historical data, serial sampling of enzymes, and electrocardiograph (ECG) patterns were collected for more than four hours after admission into the ED. Then, patients were hospitalized or discharged. The follow-up was completed within two months.

Results: Table 1 indicates that first five variables predicting AIHD, in decreasing order of statistical significance, selected by step-wise logistic regression.

Table 1-Variables Predicting Outcome of Patients with Chest Pain

$\begin{array}{lcc}\text { Variable } & \text { Coefficient } & \text { Improvement } \mathbf{X}^{2} \\ \text { Coronary disease history } & 2.01 & 124.1 \\ \text { Age } & -0.04 & 23.3 \\ \text { Abnormal T-wave } & 1.56 & 17.4 \\ \text { Fluctuations in chest pain } & -1.08 & 16.9 \\ \text { Syncope } & 2.74 & 7.9 \\ \text { K } & -1.26 & - \\ \text { n.b. categorical variables are set yes }=1 \text { and no }=\overline{2} .\end{array}$

Table 2-Comparison of the Predictive Instrument and Physician Decision-Making.

$\begin{array}{lcc} & \begin{array}{c}\text { Predictive } \\ \text { Instrument }\end{array} & \begin{array}{c}\text { Physician's } \\ \text { Judgment }\end{array} \\ \text { FP Rate (\%) } & 20 & 24 \\ \text { FN Rate (\%) } & 17 & 10 \\ \text { Sensitivity (\%) } & 66 & 84 \\ \text { Specificity (\%) } & 90 & 83 \\ \text { Accuracy (\%) } & 81 & 84\end{array}$

$F P=$ False Positive $; F N=$ False Negative

Conclusion: This predictive instrument gives the ED physician a simple numerical probability of the likelihood of a true myocardial ischemia. It yields better specificity at the cost of increased false negatives (FN), and hence of inappropriate discharges from ED. Physician's judgment supported by the mathematical pattern, remains, at the moment, the best procedure for chest-pain diagnosis.
190

\section{Intravenous Urapidil: Efficacy and Safety in the Treatment of Hypertensive Urgencies}

Hirschl MM, Zeiner A, Frossard M, Sterz F,

Domanovits $H$, Laggner $A N$

Department of Emergency Medicine, University of Vienna

Vienna, Austria

Objective: Hypertensive urgencies are common problems in an Emergency Department. The aim of this study was to evaluate the efficacy and safety of intravenous administration of Urapidil in the treatment of hypertensive urgencies.

Methods: Forty-eight patients (age $52 \pm 12$ years) fulfilled the criteria for a hypertensive urgency and were treated with $25 \mathrm{mg}$ Urapidil intravenously. The aim of the treatment was to reduce blood pressure (BP) below $180 \mathrm{mmHg}$ systolic and $100 \mathrm{mmHg}$ diastolic within 15 minutes. If the patient did not respond to the first dose of Urapidil, a second dose of Urapidil $(12.5 \mathrm{mg}$ ) was administered 15 minutes later. Blood pressure was measured every five minutes until a stable diastolic BP was established. Side-effects of the drug and emergency treatment duration were recorded.

Results: An insufficient blood pressure reduction was seen in nine patients (18\%; BP 192/105 $\mathrm{mmHg}$ ) receiving $25 \mathrm{mg}$ Urapidil. Seven of these patients showed a sufficient reduction of BP after administration of a second dose of $12.5 \mathrm{mg}$ urapidil. Two (4\%) patients did not respond to Urapidil. In two patients, hypotension (BP $90 / 60$ and $75 / 40 \mathrm{mmHg}$ respectively) without any clinical symptoms was recorded. The emergency treatment duration was $78 \pm 13$ minutes.

Conclusion: The use of Urapidil has very high efficacy in treatment of hypertensive urgencies with a first response rate of $82 \%$. Compared to other antihypertensive drugs (nifedipine, captopril, clonidin), the response rate to Urapidil is similar or even better. Only $4 \%$ of the patients were non-responders. No severe side-effects were observed, and the emergency treatment duration was very short. It is assumed that Urapidil is a first choice drug in the emergency department setting despite its intravenous application, because the drug is highly effective (96\% responder), enables a short emergency treatment duration, and shows no severe side-effects. 